\title{
Novos campi universitários de instituições públicas: análise de uma biblioteca à luz da Ergonomia do Ambiente Construído
}

\section{New university campuses of public institutions: an analysis of a library from the perspective of the Built Environment Ergonomics}

GAEL ARAUJO

Graduando, UFPE, gael.arj7@gmail.com

TATIANE SANTOS

Graduanda, UFPE, tatianekellyferreiradossantos@gmail.com

RAPHAELA BANKS

Mestra, UFPE, raphabanks@gmail.com

BRUNO BARROS

Mestre,UFPE, barros_bruno@hotmail.com

\section{RESUMO}

O processo de difusão de universidades públicas no Brasil tem permitido levar o conhecimento a áreas mais remotas do país, fora dos tradicionais eixos das capitais. Aliado às novas tecnologias de sistemas modulares pré-moldados da engenharia civil, este processo tem tornado possível a rápida construção dos diversos tipos de edificações que compõem os centros universitários, o que inclui o espaço da biblioteca. Um ambiente destinado ao desenvolvimento de atividades de estudo e pesquisa, como uma biblioteca universitária, que se distancie das recomendações de normas de conforto ambiental e ergonômico, pode ser incapaz de fornecer bem-estar ao indivíduo, desestimulando sua permanência e comprometendo a realização das atividades indicadas para esse espaço. Dentro deste contexto, a corrente pesquisa repousou o foco na análise de uma biblioteca recém construída de uma universidade pública localizada no interior do nordeste brasileiro. Para a condução procedimental, lançou-se mão da Metodologia Ergonômica para o Ambiente Construído (MEAC), proposta por Villarouco (2007). A investigação apontou diversas incoerências no que tange ao leiaute, conforto ambiental e organização do espaço, o que tornou possível a elaboração de uma série de recomendações ergonomizadoras direcionadas à biblioteca.

PALAVRAS-CHAVE: Ergonomia do ambiente construído, análise ergonômica, biblioteca, MEAC.

\section{ABSTRACT}

The recent dissemination of new public university campuses in Brazil has allowed knowledge to be taken to more remote areas of the country, outside the traditional locations of capitals. Allied to the new technologies of precast modular systems of civil engineering, this process has made possible the rapid construction of the different types of buildings that are part of the university centers, which 


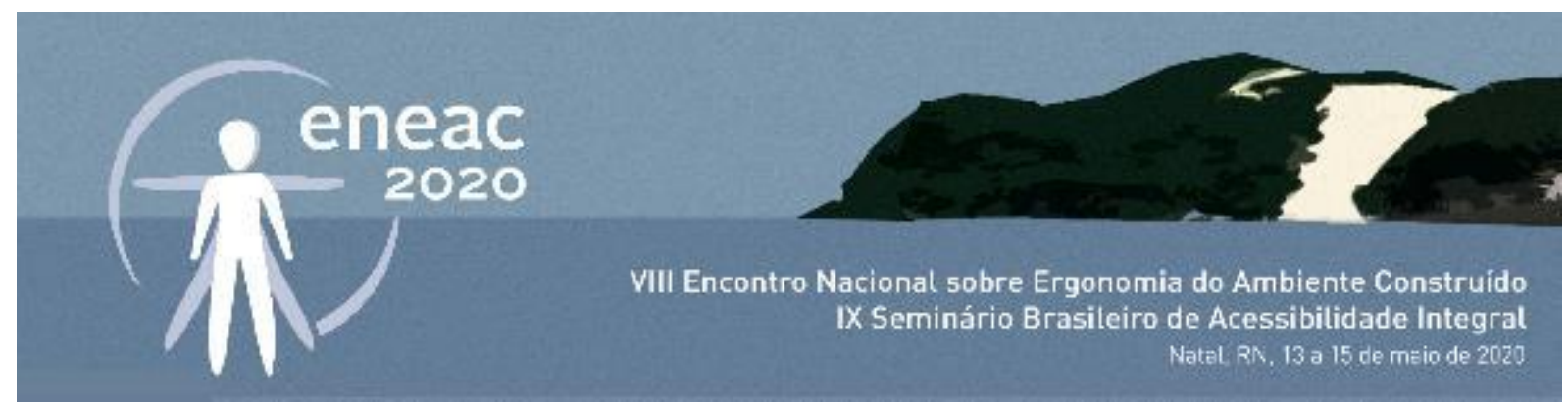

includes the library space. An environment designed for the development of study and research activities, such as a university library, which deviates from the recommendations for environmental and ergonomic comfort standards, may be unable to provide well-being to the individual, discouraging their permanence and compromising the performance of activities indicated for that space. Within this context, the current research rested the focus on the analysis of a newly built library of a public university located in the interior of northeastern Brazil. For procedural guidance, the Ergonomic Methodology for the Built Environment (MEAC), proposed by Villarouco (2007), was used. The investigation pointed out several inconsistencies in terms of layout, environmental comfort and space organization, which made it possible to develop a series of ergonomic recommendations directed to the library.

KEYWORDS: Built environment ergonomics, ergonomic analysis, library, MEAC.

\section{INTRODUÇÃO}

A abertura de novos campi universitários federais em cidades do interior do Brasil tem proporcionado o acesso à educação superior gratuita por parte de determinadas faixas populacionais, as quais não teriam condições econômicas de viajar ou residir nas capitais dos estados para estudar. De fato, a engenharia civil chegou a um ponto de evolução tecnológica onde a edificação de novos prédios acontece de maneira muito mais rápida, por meio de estruturas modulares. Tais estruturas erguem edificações de forma rápida, mas não necessariamente adequadas às necessidades, características e limitações dos usuários locais. As considerações humanas de desempenho das atividades em edifiçções de ensino estão diretamente relacionadas à qualidade do processo de ensino aprendizagem destes locais e, neste ponto, a Ergonomia surge como forte aliada no processo de investigação e adequação dos espaços.

A Ergonomia utiliza-se de metodologias para avaliação e promoção de conforto ambiental para ambientes de utilização humana, buscando adequá-lo aos usuários e garantir o bem-estar durante sua estadia e atividades. O presente artigo é resultado da aplicação da Metodologia Ergonômica para o Ambiente Construído (MEAC), concebida por Villarouco (2007), sob o espaço de uma biblioteca recentemente instalada em uma universidade pública de uma cidade do interior do nordeste brasileiro. Com isso, empregou-se as etapas de avaliação física e cognitiva da metodologia à biblioteca, a qual acolhe as demandas de sua comunidade acadêmica.

A biblioteca foi instalada a menos de 3 anos no pavimento térreo e $1^{\circ}$ andar do prédio administrativo do Campus, localizada no centro dos blocos de salas de aula. A investigação descrita na corrente pesquisa se concentrou no pavimento térreo da biblioteca, o qual comporta quatro espaços distintos para execução de tarefas: acervo, consulta eletrônica, área de estudo e setor de atendimento.

A análise realizada teve como objetivo identificar inadequações presentes no local, bem como pontos passíveis de melhorias sob o ponto de vista da Ergonomia. Para tanto, foram realizadas aferições e levantamentos de informações físicas e perceptivas sobre o ambiente, considerando a interação estabelecida com o usuário, o que promoveu a identificação das falhas ergonômicas presentes na biblioteca. Dessa forma, pôde-se elaborar uma lista de recomendações ergonômicas e, a partir de então, uma proposta projetual conceitual baseada nas recomendações ora tecidas. 


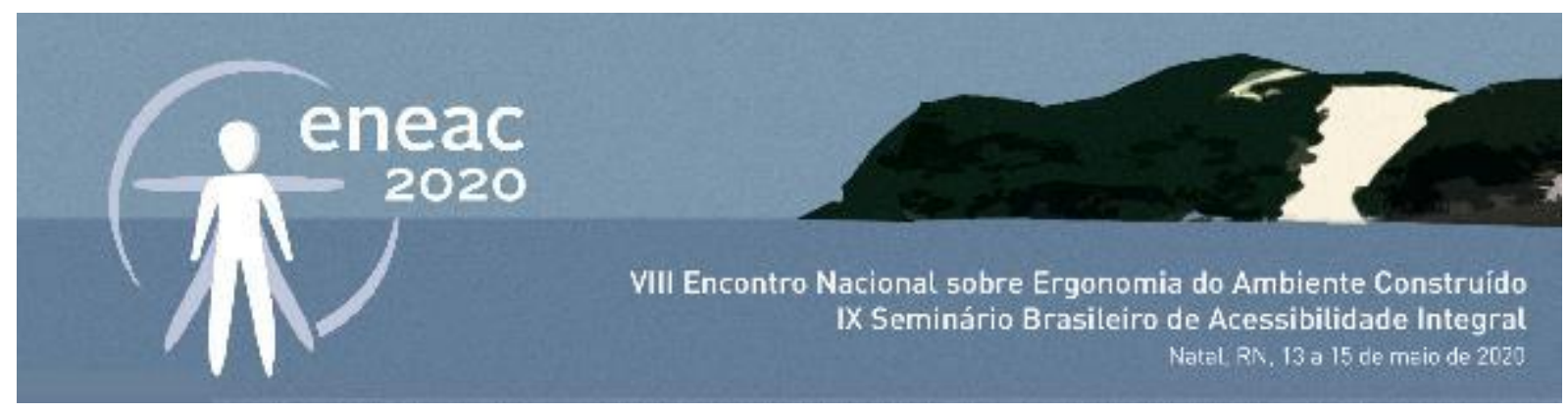

\section{FUNDAMENTAÇÃO TEÓRICA}

Dentre as diversas tipologias de ambientes de ensino superior, podemos destacar o conceito de Biblioteca Universitária (BU). Segundo Alcântara et al. (2012), a Biblioteca Universitária é a interface social que media o conhecimento à comunidade acadêmica, administrando seu patrimônio informacional e promovendo o exercício educativo. $\mathrm{O}$ ambiente da biblioteca depende de boas condições que provocam nos usuários a sensação de habitação e estímulo ao desenvolvimento de suas atividades, onde a configuração do leiaute determinará o conforto e adequação através da melhor distribuição do espaço para comportar mobiliário, acervo, espaço funcionais (para pesquisa, estudo e trabalho), considerando ainda a sinalização e fatores ambientais, como iluminação, temperatura, acústica e cores (VASCONCELOS et al., 2009; PIMENTEL et al., 2007).

Diversos elementos internos que compõem as bibliotecas merecem atenção sob o ponto de vista da Ergonomia. Vasconcelos et al. (2009) e Emerim (2016) trazem algumas observações, apontado que a conservação dos livros depende do controle da temperatura, o isolamento acústico contribui para a concentração dos usuários e a iluminação assegura a boa visibilidade, segurança e orientação aos usuários, promovendo também a ambientação dos espaços criando sensações psicoemocionais. Em relação ao mobiliário da biblioteca, deve-se optar pela simplicidade, resistência, Ergonomia, bom acabamento, extremidades arredondadas e evitar frestas, para acomodar os usuários com conforto às mesas, cadeiras (com suporte lombar e estofamento) e estantes de metal (MINUZZO, 2004). A NBR 5413/1992 determina que o índice de iluminância adequado para uma sala de aula deve estar entre 300 e 500 Lux. Para lida (2005), uma zona de conforto térmico apropriada aos padrões brasileiros tem temperatura efetiva entre $20^{\circ}$ e $24^{\circ} \mathrm{C}$, com umidade relativa de 40 a $60 \%$, com a velocidade do ar na ordem $0,2 \mathrm{~m} / \mathrm{s}$ e as diferenças de temperatura em um mesmo ambiente não devem ser maiores a $4^{\circ} \mathrm{C}$. A NR-17 diz que o índice de temperatura efetiva deve estar entre $20^{\circ}$ e $23^{\circ} \mathrm{C}$ e que a velocidade do ar não deve ser superior a 0,75m/s. A NBR 10152-Níveis de Ruído para Conforto Acústico, recomenda que o nível de ruído no ambiente de estudolay deve estar compreendido entre 35 e $45 \mathrm{~dB}$.

As cores tem a capacidade de retirar a monotonia do ambiente e ajudar a concentração do usuário, influenciando sua estimulação mental e produtividade (GONÇALVES, 2016). Para Souto et al. (1999 apud CAPRI et al., 2012), à biblioteca deve-se aplicar cores claras, suscitando iluminação, concentração e tranquilidade, uma vez que as cores escuras provocam agitação e cansaço aos usuários, sendo estas indicadas apenas ao piso e a decoração. Contudo, as cores devem ser dosadas, pois o excesso de cores frias torna o ambiente depressivo (AZEVEDO et al., 2011). O ideal é combinar uma cor fria com uma cor quente, levando em consideração que há cores mais indicadas para ambientes de aprendizagem, como o laranja, que expressa jovialidade e alegria, provocam estímulo psicológico, prazer, desinibição, abertura ao novo, bem estar físico e equilibro no trabalho (LACY, 2000; SANTOS et al., 2017).

\section{METODOLOGIA}

Para a realização desse trabalho foi adotada a Metodologia Ergonômica para o Ambiente Construído (MEAC) desenvolvida por Villarouco (2007). A MEAC é composta por quatro etapas, 1. Análise Física (a qual compreende a Análise Global do Ambiente; a Identificação da Configuração do Ambiental; e a 


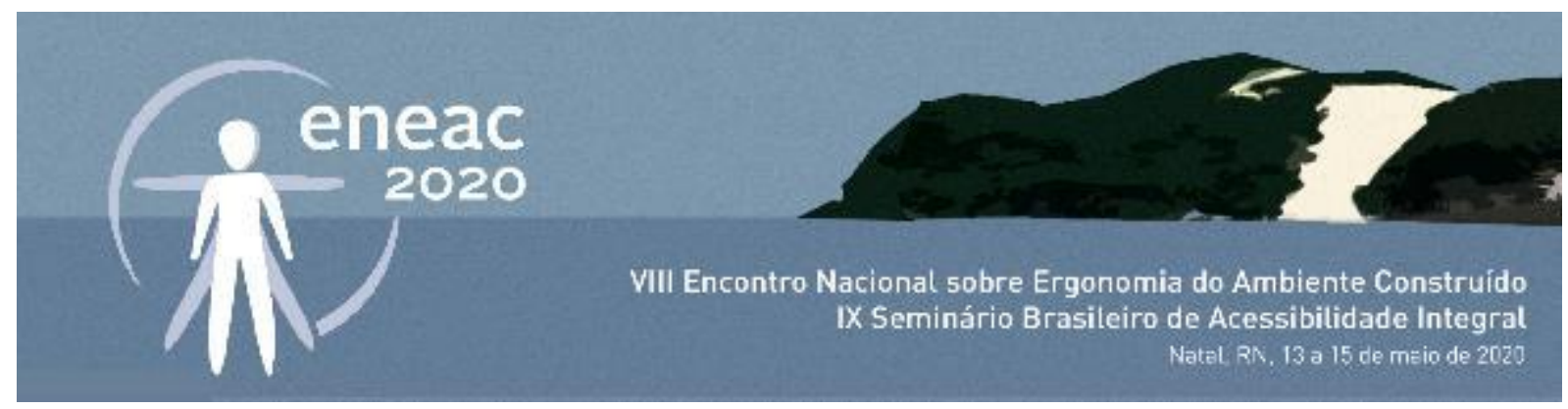

Avaliação do Ambiente em Uso), 2. Percepção Ambiental do Usuário, 3. Diagnóstico Ergonômico do Ambiente, e 4. Proposições Ergonômicas para o Ambiente.

A Análise Global do ambiente possibilita ter ideia da configuração espacial do ambiente e se analisa as atividades desenvolvidas. Esta etapa possibilita uma visão sistêmica do ambiente a partir do conhecimento dos materiais, do pessoal que usa o ambiente, do desperdício de tempo e equipamentos utilizados, dos fluxos, dos processos e produtos principais, para assim, entender o que é feito e como é feito o ambiente (Villarouco, 2009).

Na fase de Identificação da Configuração do Ambiente, é estudada a análise da tarefa para conhecer as condições físico-ambientais. Através do conhecimento do trabalho realizado, das tarefas desenvolvidas, das características que devem conter os postos e estação de trabalho, maquinário, equipamentos e tecnologias utilizadas. (Villarouco, 2007).

Na fase de Avaliação do Ambiente em Uso no Desempenho das Atividades, Villarouco (2009) recomenda que seja feita uma avaliação para saber o quanto facilitador e dificultador se torna o ambiente no momento da realização das tarefas. Nessa fase, analisa-se o desenvolvimento das atividades focando no espaço construído, com o objetivo de verificar a interferência positiva ou negativa do espaço construído no desempenho das atividades.

Na fase de Percepção Ambiental, a autora diz que é necessário fazer um estudo da percepção que os usuários têm do ambiente que utiliza. Para se entender melhor a percepção do usuário, é importante utilizar o auxílio da psicologia ambiental como ferramenta auxiliar para identificar as características de caráter mais cognitivo e perceptual.

Por fim, a MEAC é concluída com mais 2 etapas, a de Diagnóstico Ergonômico do Ambiente e a de Proposições Ergonômicas para o Ambiente, as quais irão apresentar os resultados das avaliações e expor recomendações de alteração direcionadas ao ambiente em questão.

\section{RESULTADOS}

\section{Análise Física}

\section{Análise global do ambiente}

A Biblioteca selecionada para estudo localiza-se no pavimento térreo do bloco administrativo do Campus da Universidade, consistindo em um espaço institucional onde a comunidade universitária e servidores desempenham atividades pedagógicas, com caráter informativo e instrumental sobre o processo de formação acadêmica e cultural. Suas atividades ocorrem no período das 8 hs às 21hs30mins, podendo ser agrupadas em quatro categorias distintas:

- Setor do acervo: onde estão acondicionados os livros e demais títulos da biblioteca, disponíveis para consultas locais ou empréstimos.

- Setor de consulta eletrônica: área com computadores onde os usuários podem pesquisar e renovar títulos, entre outras ações;

- Setor de atendimento: composto pelos postos de trabalho, onde os bibliotecários operacionalizam suas principais atividades, entre elas o atendimento ao público; 


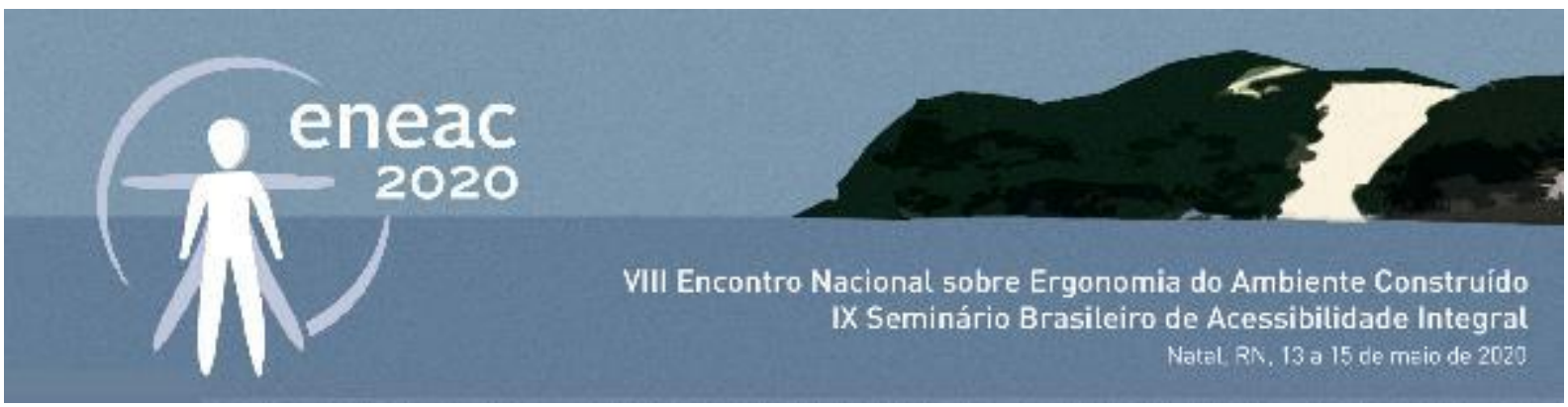

- Setor de estudo: consiste na área reservada para os estudantes realizarem consultas locais ou estudarem individualmente.

O espaço interno da biblioteca é retangular e esteticamente monótono, sem grandes variações cromáticas (cores neutras e frias) ou de texturas, tanto nos elementos arquitetônicos quando no mobiliário. Mas parece amplo, apesar da ocupação predominante de grandes estantes de livros (figura 1).

Figura 1: Visão geral da biblioteca selecionada para análise.

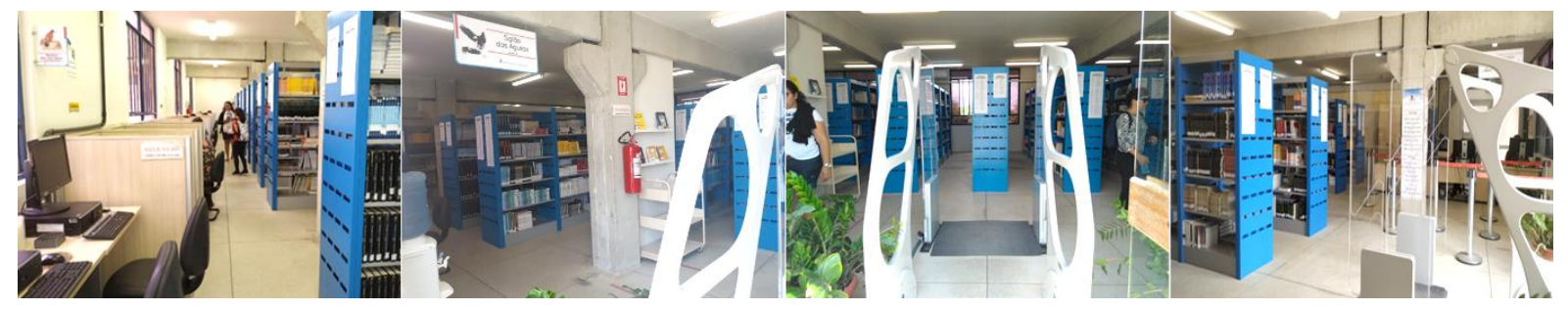

Fonte: Capturado pelos autores para a pesquisa.

O espaço dispõe de uma porta de acesso, do tipo giro, com uma folha em vidro, um vão de acesso aos banheiros e onze janelas basculantes na cor azul, com vidro transparente e películas adesivas, auxiliando na iluminação diurna e na ventilação do ambiente interno e na visualização do ambiente externo. Pode-se ressaltar negativamente, a existência de pilares e fiações elétricas expostas, que atrapalham a circulação e variação do leiaute e oferece risco à segurança, respectivamente.

\section{Identificação da configuração ambiental}

A Biblioteca estende-se por uma área de $295,5 \mathrm{~m}^{2}$, frequentada por uma quantidade variável de usuários que fazem uso do espaço de diversas formas, acomodando-se ao mobiliário ou transitando pelos corredores formados entre as estantes de livros, principalmente. Quanto ao acabamento, as paredes (em alvenaria) e teto são emassados e pintados na cor branco gelo e o piso em granilite polido na cor cinza. Referente a configuração elétrica, esta é composta por tubulação do tipo exposta, e eletrodutos na cor preta, fixados às paredes e ao piso. Apresentando ainda, um sistema de sinalização com a temática de aves brasileiras que pode ser aperfeiçoado.

Através da análise da planta baixa do pavimento térreo do bloco administrativo onde está locada a biblioteca (figura 2), observa-se o leiaute do ambiente. 


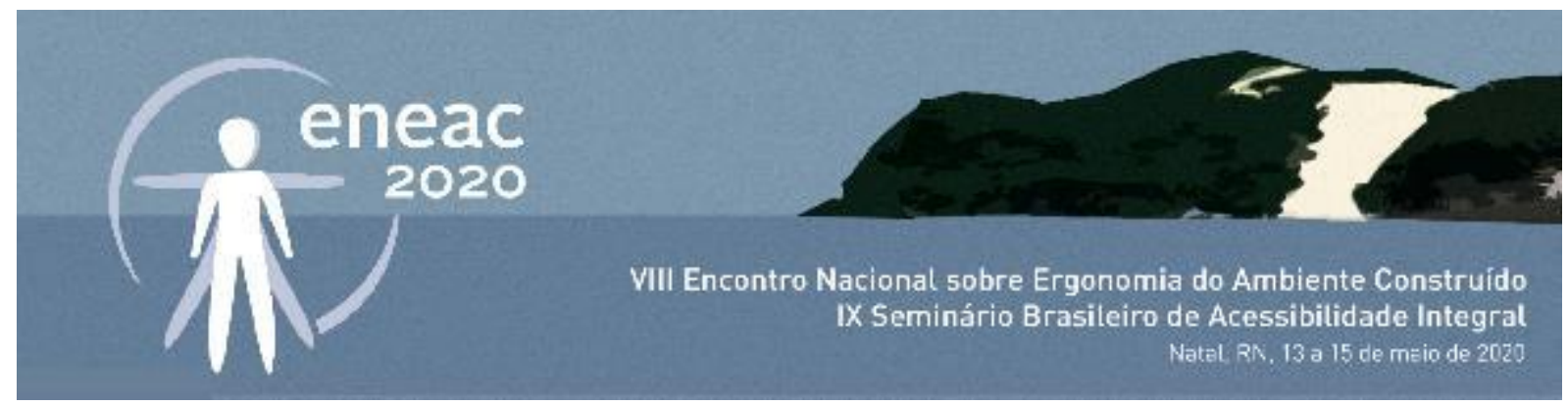

Figura 2: Planta baixa do pavimento terreo do bloco administrativo - sanitários e depósitos, biblioteca, infraestrutura e escadas.

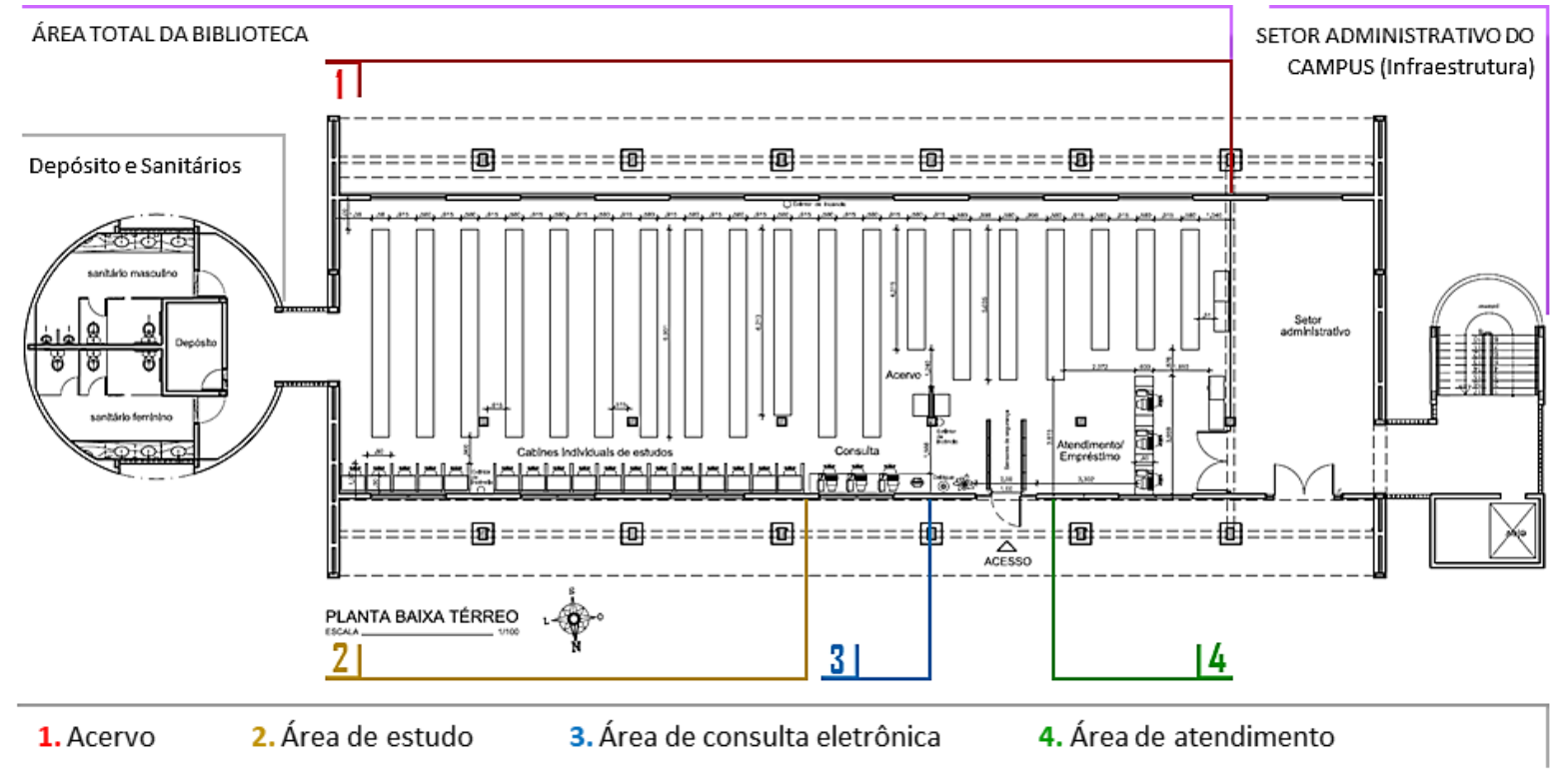

Fonte: Elaborada pelos autores do artigo a partir da planta baixa cedida pela infraestrutura do Campus (2020).

O espaço é composto por 4 setores (área de estudo, consulta eletrônica, acervo e atendimento), nos quais pode-se percebe a disposição do mobiliário e elementos arquitetônicos pelo espaço. $\mathrm{O}$ acervo ocupa a maior área do espaço, comportando os pilares, extintores de incêndio, 2 carrinhos de recolhimento de livros e as dezenove estantes de chapa metálica nas cores cinza e azul, com dimensões de $0.58 \mathrm{~m}$ de largura e $2.00 \mathrm{~m}$ de altura. O Setor de estudos, encontra-se a esquerda da porta de acesso, composto por 17 cabines individuais em MDF revestido por laminado melamínico em textura de madeira clara, com peças metálicas, encaixes na cor alumínio e dimensões de $0.80 \mathrm{~m}$ de largura, $0.50 \mathrm{~m}$ de profundidade e $0.75 \mathrm{~m}$ de altura. Há ainda 15 cadeiras com estrutura metálica em preto e estofado em couro sintético na cor verde escuro e duas tomadas por cabine, abaixo do tampo e próximas ao piso.

O setor de consulta eletrônica, também a esquerda da porta de acesso, dispõe de 4 mesas com tampo em MDF revestido por melamína em textura de madeira e pés metálicos pintados de cinza claro, 3 cadeiras com estrutura metálica em preto e estofado em couro sintético na cor verde escuro, 1 impressora, 2 estabilizadores, 3 computadores (desktops) na cor preta e um gela-água. Quanto ao setor de atendimento, localiza-se à direita da porta de acesso, constituído por 3 mesas, 3 gaveteiros, e 1 armário, ambos em MDF revestido por melamína em textura de madeira, além de 1 impressora, 3 computadores, guias móveis de organização de filas, 1 estante de chapa metálica pintada em azul e cinza e 3 cadeiras com estrutura metálica em preto e estofado em couro sintético na cor verde escuro.

A Biblioteca oferece algumas condições de acessibilidade, usufruindo de piso nivelado no acesso principal, dimensões adequadas na porta de acesso, duas cabines exclusivas para cadeirantes e circulação interna variável entre $0.90 \mathrm{~m}$ e $1.08 \mathrm{~m}$ de largura, compatível com o mínimo estabelecido pela NBR 9050/ 2004, que trata da passagem de cadeirantes ou de pessoas em pé - com bengala, 


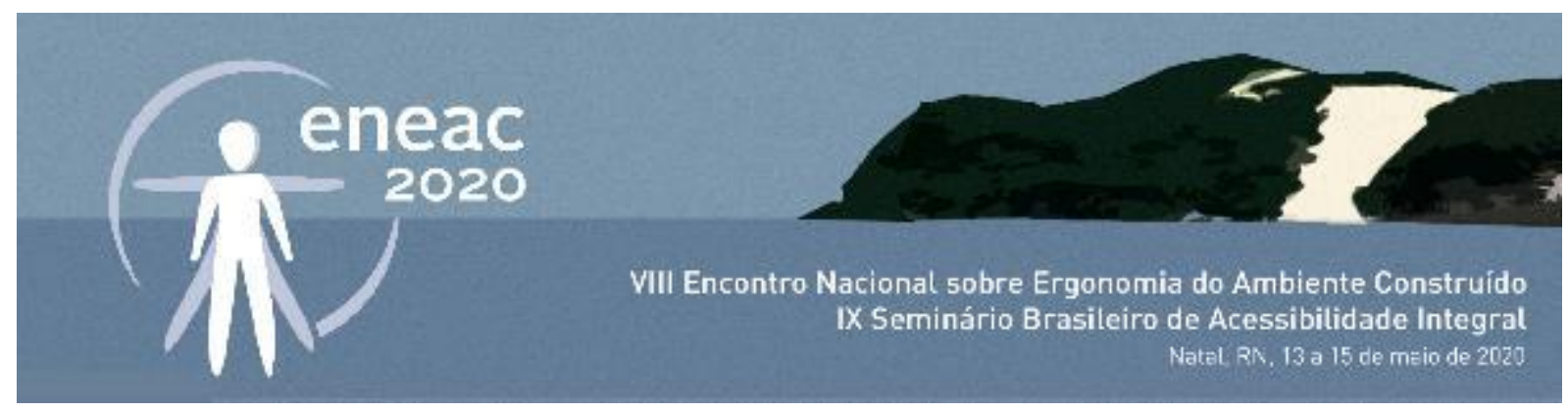

muletas, andador com rodas, cão guia, etc. Contudo, não possui espaço para rotação de cadeirantes, piso podotátil e escrita em Braille no acervo para deficientes visuais.

Quanto ao suporte social, a biblioteca está centralizada na área total da universidade, próxima as salas de aula, ao prédio de assuntos estudantis, ao restaurante, a parada de ônibus, a quadra poliesportiva, ao estacionamento, posto de saúde e as lanchonetes. Oferecendo recursos de conexão com a internet e sanitários, conforme a planta baixa (figura 2).

Para avaliação do conforto ambiental foi estabelecido três pontos (A, a leste-Norte; B, a sul; e C, a oeste) para aferimento dos níveis de iluminação, ventilação e ruído, nos turnos da manhã, tarde e noite, considerando as características arquitetônicas e equipamentos da biblioteca, como janelas, cobogó, portas e vão de acesso, como mostra a figura 3.

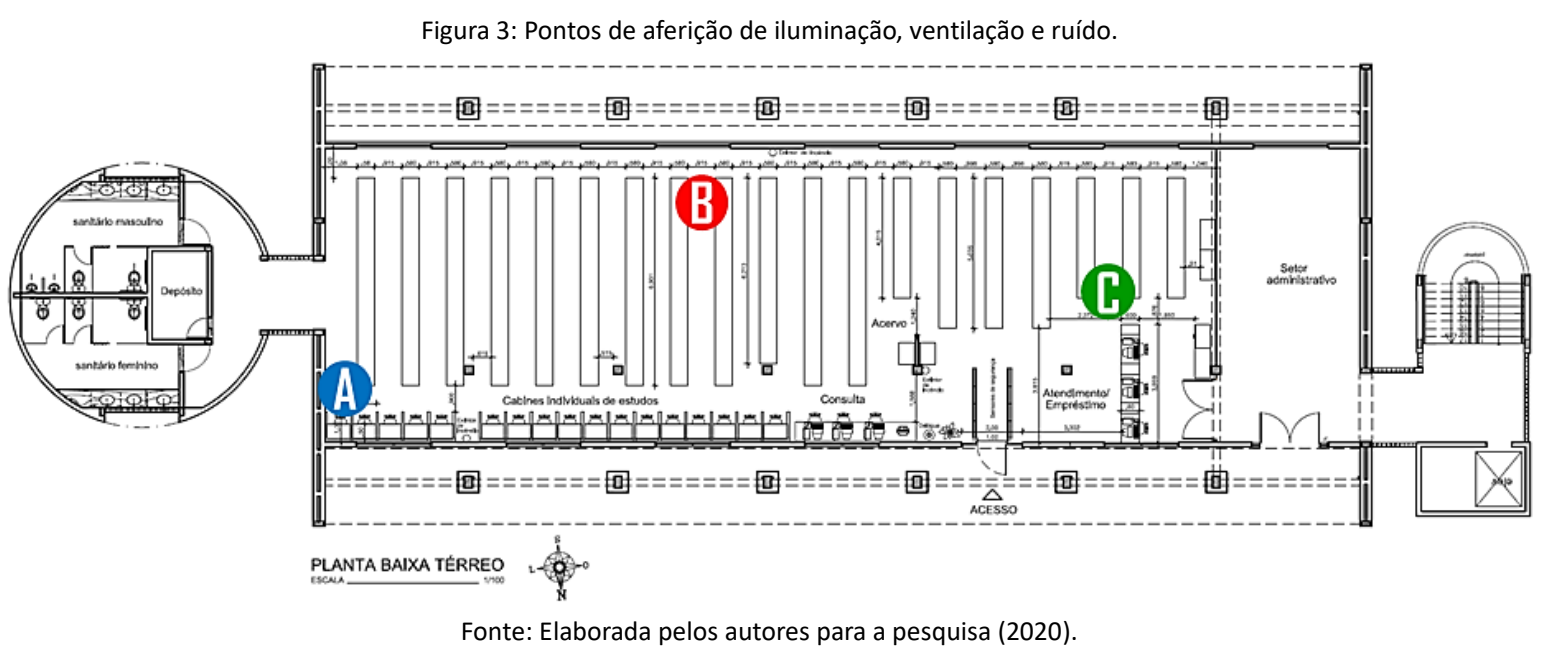

Para verificação dos níveis de iluminação do ambiente, foi utilizado um Luxímetro devidamente calibrado, aplicando-se no ponto $\mathrm{A}$ (cabines de estudo), onde há agrupamento de janelas proporcionando a projeção de luz natural para o interior, no ponto $B$, localizado no acervo sem presença de janelas e no ponto $C$, encontrando-se numa interseção entre acervo e área de atendimento. Os resultados para esta característica foram positivas, apenas no turno noturno, enquadrando-se nas recomendações da NBR 5413/ 1992, conforme expõe a tabela 1.

Tabela 1: Níveis de iluminação do ambiente em lux.

\begin{tabular}{|c|c|c|c|c|c|c|c|}
\hline \multirow{2}{*}{ LOCAL } & \multicolumn{3}{|c|}{ MEDIÇÃO } & \multicolumn{3}{|c|}{ Situação } & \multirow{2}{*}{$\begin{array}{c}\text { RECOMENDAÇÃO } \\
\text { NBR 5413/ } 1992\end{array}$} \\
\hline & Manhã & Tarde & Noite & Adequado (A) & & do (I) & \\
\hline Ponto A & $780 \operatorname{lux}$ & $760 \operatorname{lux}$ & $720 \operatorname{lux}$ & \begin{tabular}{l|l}
$\mathrm{I}$ & \\
\end{tabular} & 1 & A & \multirow{3}{*}{$300-500-750$ lux } \\
\hline Ponto B & $715 \operatorname{lux}$ & $710 \operatorname{lux}$ & $700 \operatorname{lux}$ & A & $A$ & $A$ & \\
\hline Ponto C & 760 lux & 750 lux & 720 lux & 1 & $A$ & $A$ & \\
\hline
\end{tabular}

Na medição de temperatura foram utilizados um termômetro e um anemômetro devidamente calibrados, nos mesmos pontos mencionados e também nos três turnos. Observou-se que a temperatura só estava dentro do recomendado nos pontos $\mathrm{B}$ e $\mathrm{C}$ no período noturno, com 


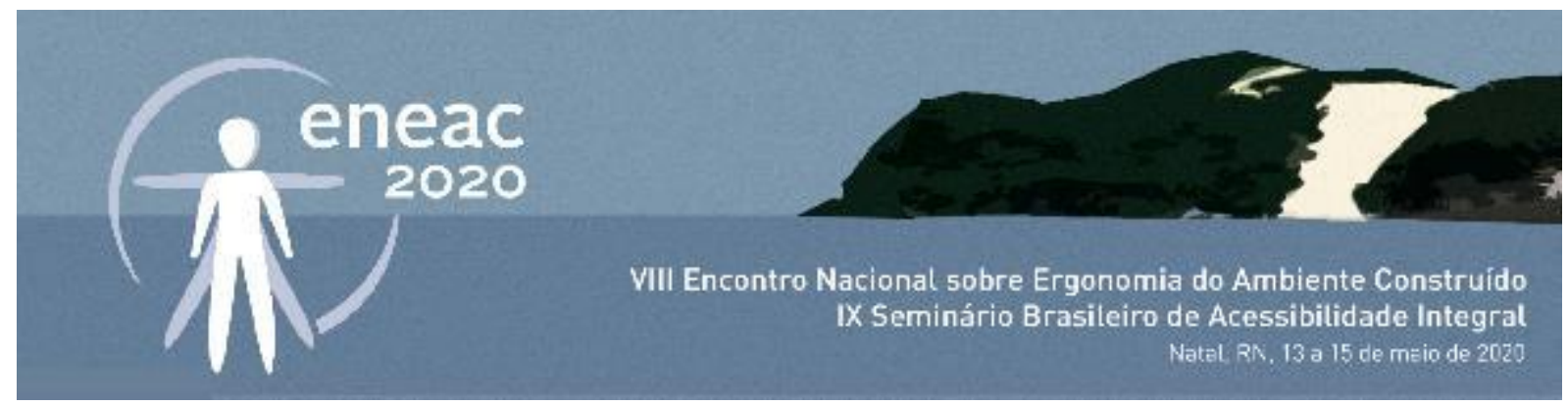

temperaturas de $26^{\circ}$ e $27^{\circ} \mathrm{C}$, tornando o ambiente inadequado, visto que o limite determinado pela NBR $1640 / 1980$ é $27^{\circ} \mathrm{C}$ e a maioria dos valores ultrapassaram esse limite, conforme expõe a tabela 2.

Tabela 2: Níveis de temperatura do ambiente em ${ }^{\circ} \mathrm{C}$.

\begin{tabular}{|c|c|c|c|c|c|c|c|}
\hline \multirow{2}{*}{ LOCAL } & \multicolumn{3}{|c|}{ MEDIÇÃO } & \multicolumn{3}{|c|}{ Situação } & \multirow{2}{*}{$\begin{array}{c}\text { RECOMENDAÇÃO } \\
\text { NBR } 6401 / 1980\end{array}$} \\
\hline & Manhã & Tarde & Noite & Adequado $(\mathrm{A})$ & & do (I) & \\
\hline Ponto A & $30 \circ \mathrm{C}$ & $29 \circ \mathrm{C}$ & $29 \div C$ & \begin{tabular}{l|l} 
& \\
\end{tabular} & 1 & 1 & \\
\hline Ponto B & 29ㅇ C & $28 \div \mathrm{C}$ & $26 \div C$ & 1 & $\mathrm{I}$ & $A$ & $\begin{array}{l}24-\mathrm{C}-26-\mathrm{C} \\
\text { limite } 27^{\circ} \mathrm{C}\end{array}$ \\
\hline Ponto C & $30 \circ \mathrm{C}$ & $28 \circ \mathrm{C}$ & $27{ }^{\circ} \mathrm{C}$ & 1 & I & A & \\
\hline
\end{tabular}

Para medição do ruído, manteve-se o mesmo procedimento das aferições anteriores para preservação dos resultados. Para essa medição contou-se com o auxílio de um decibelímetro adequadamente calibrado. Durante as medições de ruído foi observado que nos três horários de funcionamento, os níveis de ruído presentes na biblioteca ultrapassam as recomendações da NBR 1015/1987. O ideal para esse atributo é de $30-45 \mathrm{~dB}$, o que torna o espaço inadequado e interveniente a concentração. A tabela 3 apresenta os resultados.

Tabela 3: Níveis de ruídos do ambiente em decibéis (dB).

\begin{tabular}{c|c|c|c|c|c|c|c|c}
\multirow{2}{*}{ LOCAL } & \multicolumn{4}{|c|}{ MEDIÇÃO } & \multicolumn{3}{c|}{ Situação } & RECOMENDAÇÃO \\
\cline { 2 - 7 } & Manhã & Tarde & Noite & \multicolumn{2}{c}{ Adequado (A) } & \multicolumn{2}{|c|}{ Inadequado (I) } & NBR 10152/1987 \\
\hline Ponto A & $51.6 \mathrm{~dB}$ & $49.3 \mathrm{~dB}$ & $52 \mathrm{~dB}$ & $\mathrm{I}$ & $\mathrm{I}$ & $\mathrm{I}$ & \multirow{2}{*}{$30-45 \mathrm{~dB}$} \\
\hline Ponto B & $49.9 \mathrm{~dB}$ & $50.2 \mathrm{~dB}$ & $50.7 \mathrm{~dB}$ & $\mathrm{I}$ & $\mathrm{I}$ & $\mathrm{I}$ & \\
\hline Ponto C & $53.6 \mathrm{~dB}$ & $51.8 \mathrm{~dB}$ & $52.4 \mathrm{~dB}$ & $\mathrm{I}$ & $\mathrm{I}$ & $\mathrm{I}$ & \\
\hline \multicolumn{6}{c|}{ Fonte: Elaborada pelos autores (2020). }
\end{tabular}

\section{Avaliação do ambiente em uso}

Nesta fase verificou-se a usabilidade do espaço, percebendo os usuários em posturas corporais inadequadas, induzidas pelo dimensionamento do mobiliário e leiaute da biblioteca, como apresenta a figura 4. Em relação ao mobiliário, verificou-se problemas de inadequação provocados pelas estantes de livros, que forçam o usuário a estender seu corpo ou flexionar-se excessivamente em direção as prateleiras.

Figura 4: Ambiente interno da biblioteca sendo utilizado pelos usuários.

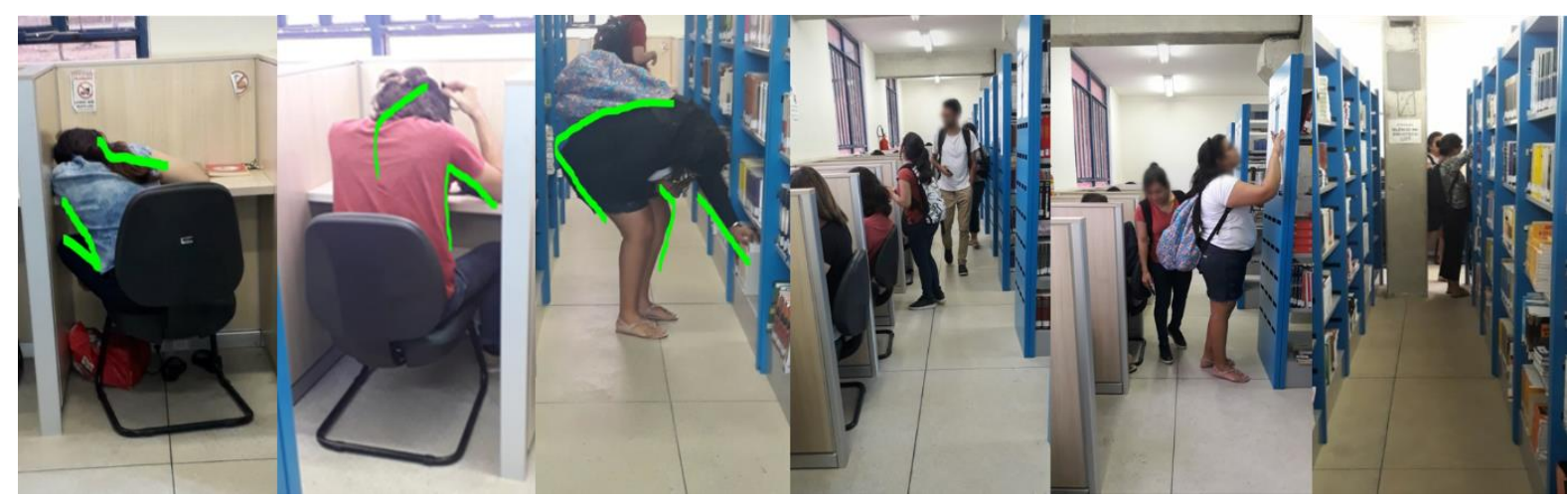

Fonte: Capturada pelos autores do artigo (2020) 


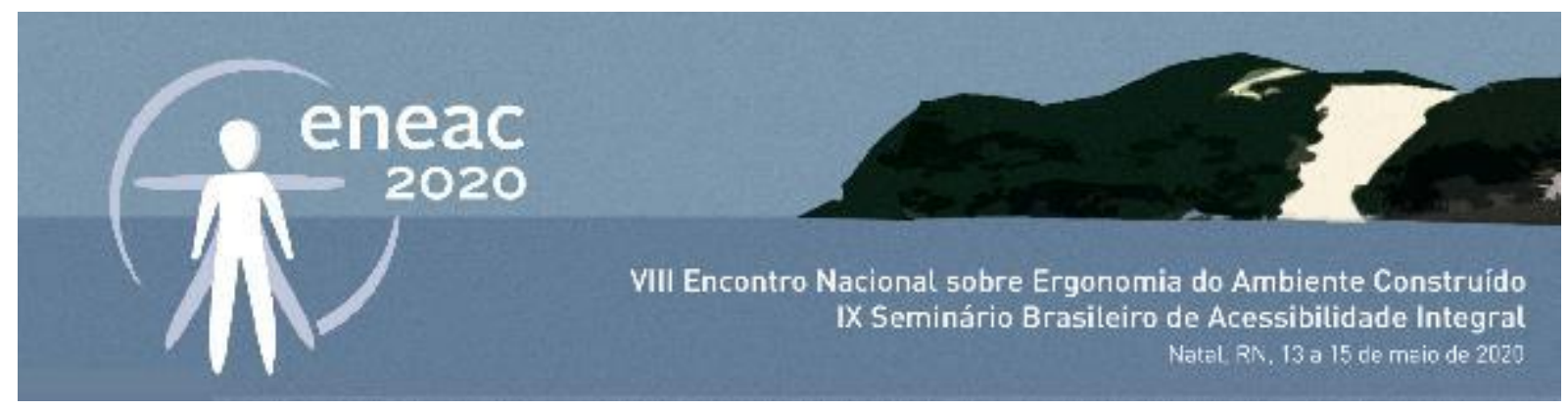

Muitas das dimensões do mobiliário encontraram-se em desacordo com recomendações de Panero e Zelnik (2016), que indicam a altura máxima de 1.75,3m para um alcance confortável das prateleiras, visto que a prateleira mais alta está a $1.77 \mathrm{~m}$. Destacou-se igualmente a inacessibilidade de uso - por deficientes e não deficientes - das tomadas das cabines de estudo, que provocam esforço cervical e lombar e geram risco de pancadas e contusões em áreas diversas da cabeça, durante o acesso as tomadas elétricas que encontram-se abaixo do tampo no rodapé da cabine. As cadeiras são outro ponto de atenção, onde os usuários assumem uma flexão excessiva da coluna vertebral, podendo levar à dores no pescoço, cervical e lombar, evoluindo ao desgaste dos discos intervertebrais dessas regiões, influenciado pela altura elevada $(46 \mathrm{~cm})$ do assento. Observou-se ainda, a possibilidade de compressão da parte posterior das coxas e possível dificuldade de vascularização sanguínea da região poplítea, devido ao uso prolongado da cadeira que ainda apresenta $48 \mathrm{~cm}$ de profundidade. Essa inadequação é justificada pela inconformidade com as definições de Panero e Zelnik (2016), que recomendam as dimensões de 39,9 a $43,2 \mathrm{~cm}$ altura e 43,3 a $43,9 \mathrm{~cm}$ de profundidade para 0 assento da cadeira.

Quanto ao leiaute, observam-se obstáculos limitantes da circulação, ora momentâneo (outros usuários) ora permanente (pilastras, mobiliário, equipamentos). Neste ponto, avaliou-se o fluxo de circulação horizontal do ambiente para percepção dos aspectos antropométricos desse tipo de circulação, onde foram inseridos modelos antropométricos na planta baixa da biblioteca em sua configuração atual. Os manequins antropométricos determinaram a situação verificada, sendo o verde indicativo de uma circulação adequada, o amarelo sinalizando atenção com algum nível de risco e vermelho, indicando uma circulação inadequada, como apresenta a figura 5.

Figura 5: Avaliação da circulação da biblioteca.

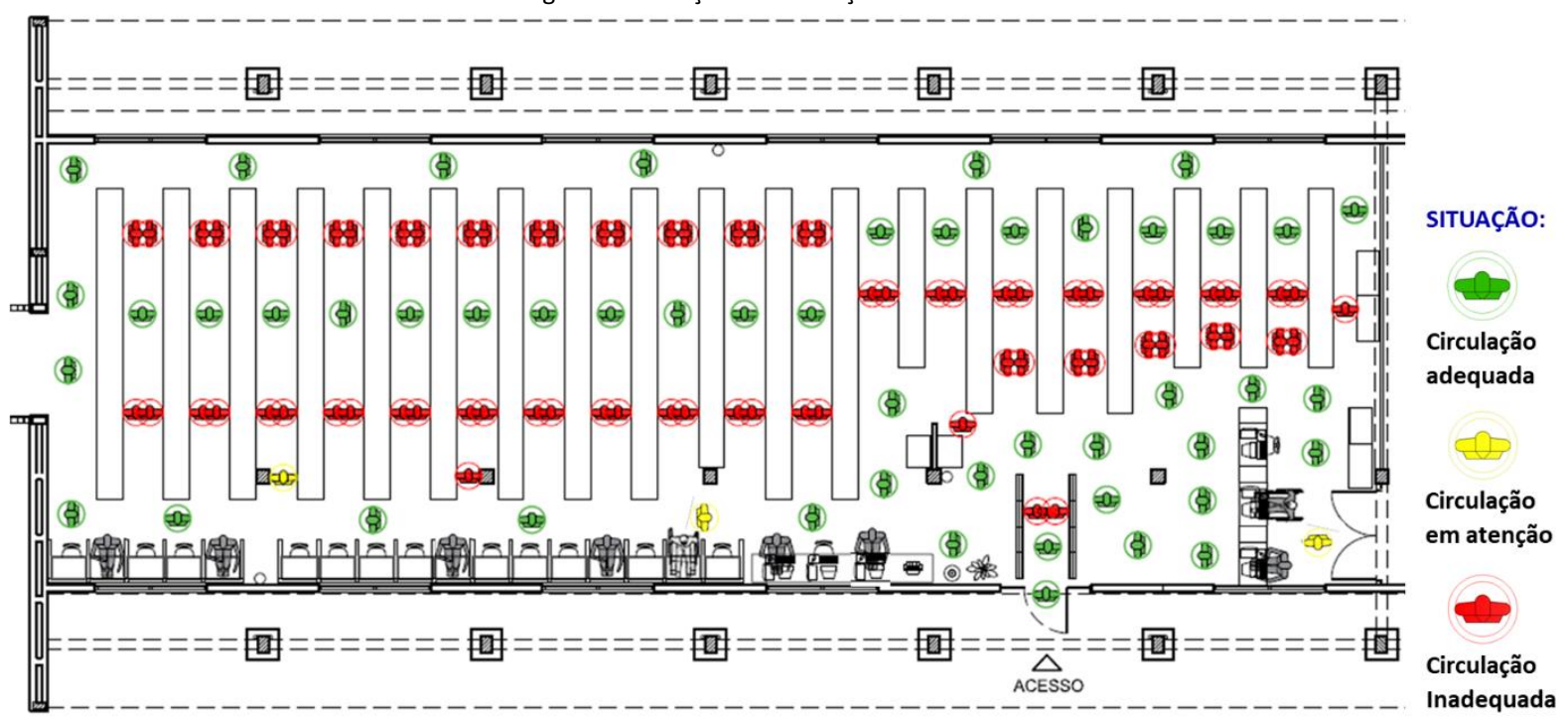

Fonte: Elaborada pelos autores (2020).

Apesar do ambiente conter corredores com 90cm à 1,08m de largura, harmônicos NBR 9050/2004, que indica $60 \mathrm{~cm}$ para passagem de um indivíduo sem órteses, e circulação periférica, concluiu-se que 


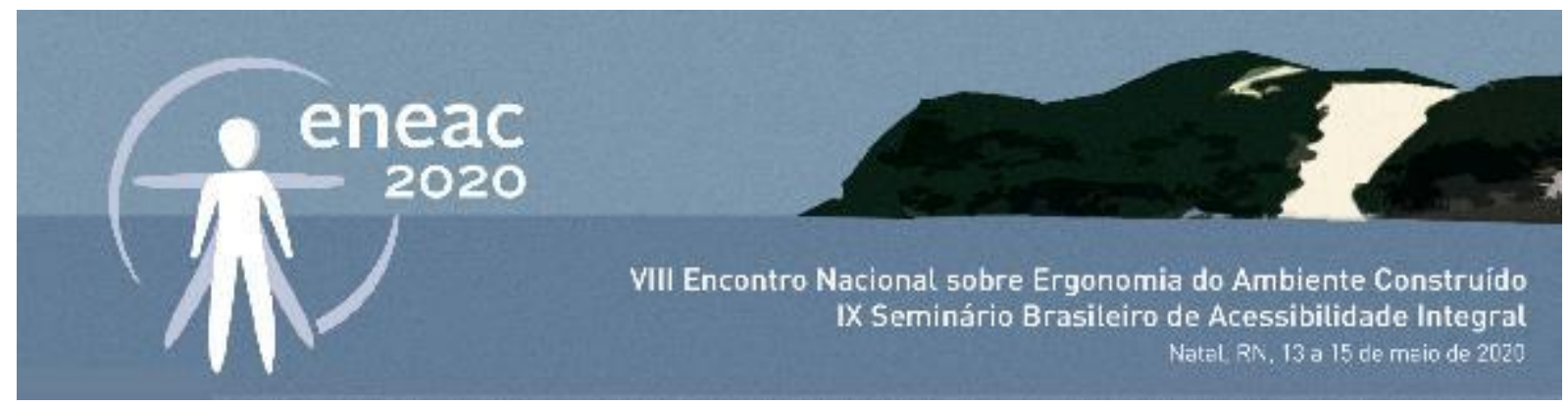

a circulação é adequada apenas nos casos em que o transeunte trafega sozinho pela maior parte do espaço, expondo uma situação inadequada quando há o uso simultâneo de mais usuários. Resultado igualmente percebido na simulação com modelos antropométricos de cadeirantes (figura 6), apresentando a largura mínima de $90 \mathrm{~cm}$ para fluxo de cadeirantes, mas impossibilitando o tráfego de duas cadeiras de rodas em sentidos opostos e sua rotação, que conforme recomenda a NBR 9050/2004 precisa-se de 1,50m de diâmetro para a manobra em 360․

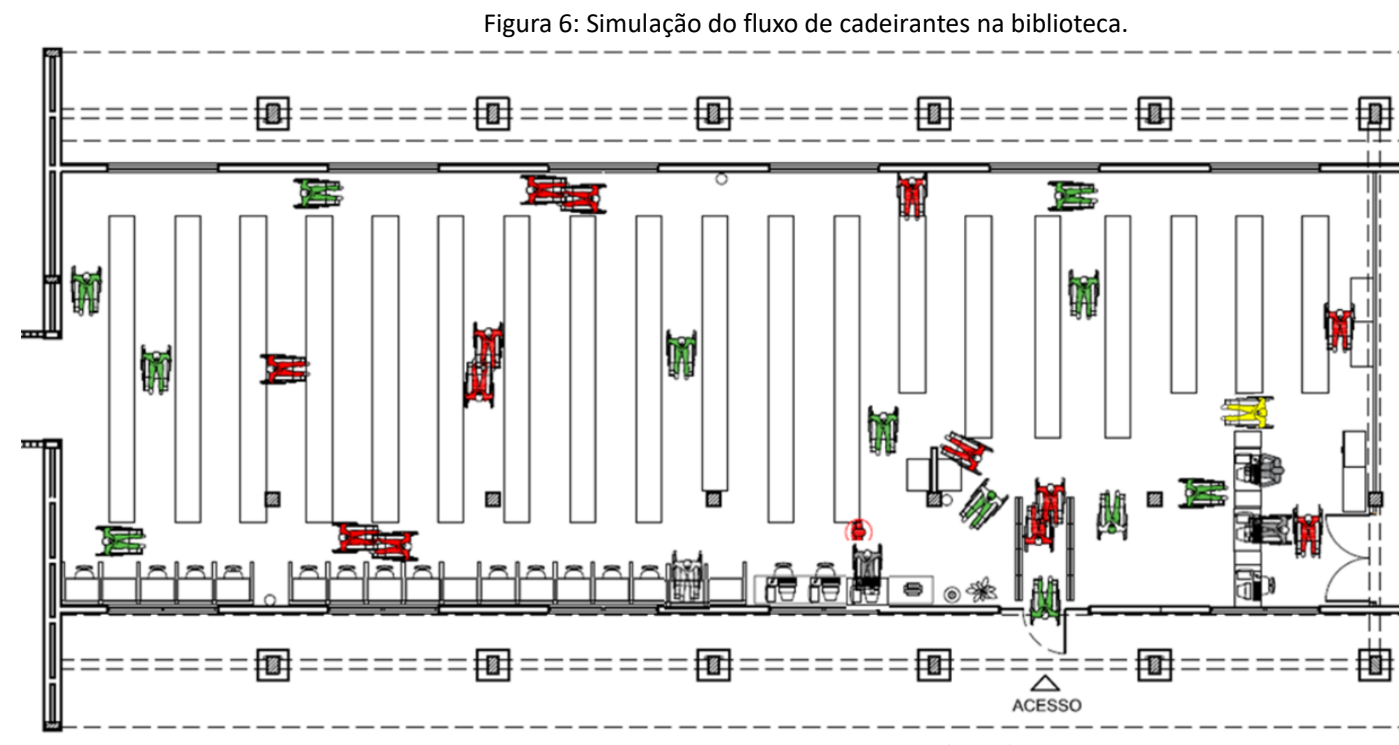

Fonte: Elaborada pelos autores (2020).
SITUAÇÃO:

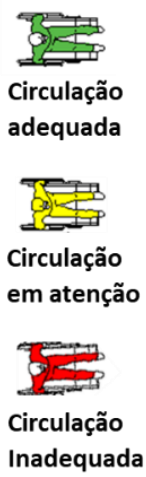

Inadequada

\section{Percepção Ambiental}

Essa etapa expõe a percepção do usuário acerca do ambiente da biblioteca selecionada para análise. Para tanto, utilizou-se do método da constelação de atributos, o qual permite identificar elementos não explícitos através de entrevistas e que podem caracterizar o ambiente físico e organizacional. A aplicação seguiu as duas etapas, sendo a primeira dedicada às características espontâneas (descrevendo um ambiente ideal) e a segunda, dedicada às características induzidas (descrevendo o ambiente real). Esse grupo foi composto por 8 mulheres e 4 homens -8 alunos, 2 professores e 2 bibliotecários - com faixa etária entre 20 a 55 anos, que utilizam o espaço por tempo variável: continuo entre os funcionários (até 6hs diárias) e menos frequente entre professores e alunos (de até $2 \mathrm{hs}$ por dia). Os voluntários dispuseram de total liberdade para elaboração de suas respostas, expressando suas opiniões e anseios diante das seguintes perguntas: 1 . Quando você pensa em uma biblioteca ideal, quais conceitos, ideias ou imagens vem à sua mente? 2. Quando você pensa na biblioteca deste campus, quais conceitos, ideias ou imagens vem à sua mente?

Com a análise das informações, foram obtidos diversos pontos de vista sobre o que era ideal e sobre as diversas falhas ergonômicas. Na figura 7 apresenta-se a constelação de atributos do ambiente ideal e do ambiente real mencionado pelos usuários. 


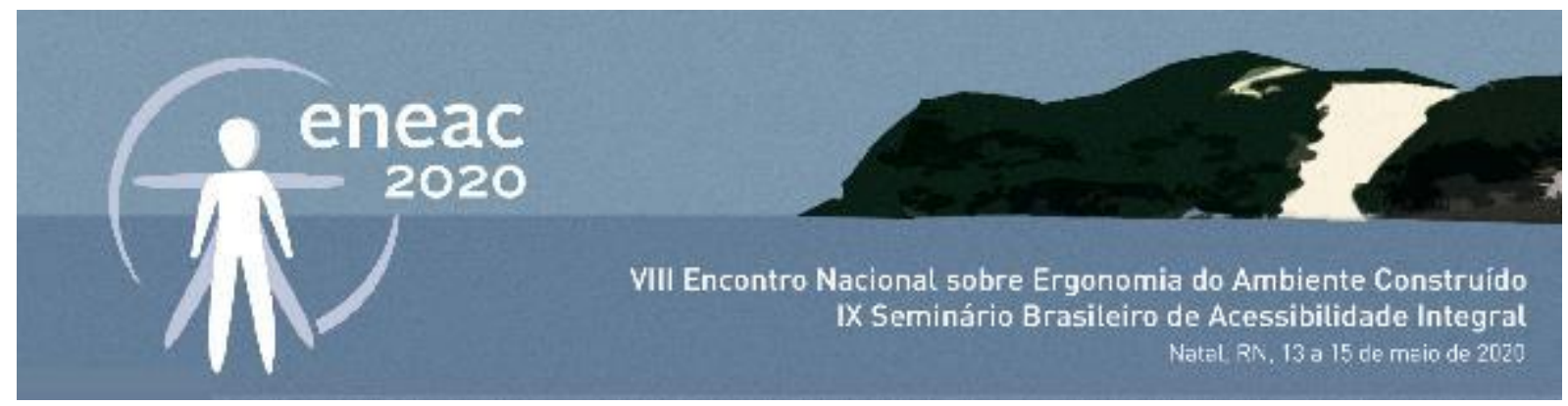

Figura 7: Comparação entre as constelações de atributos do ambiente ideal e do ambiente real do usuário.

\section{CONSTELAÇÃO-AMBIENTE IDEAL}

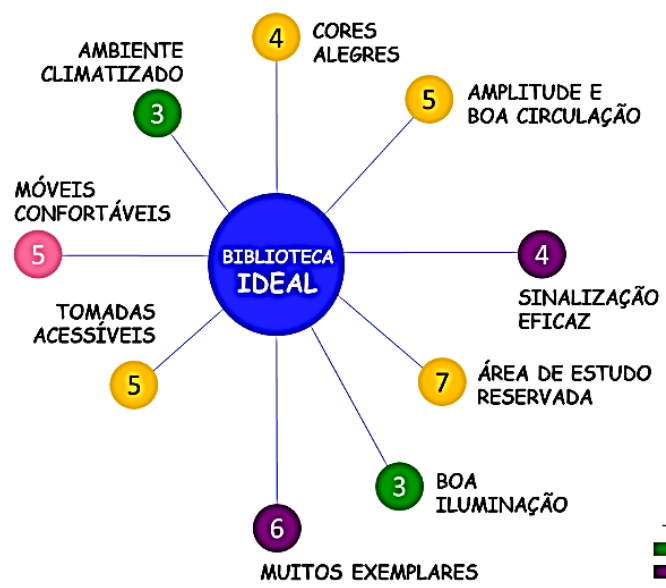

\section{CONSTELAÇÃO - AMBIENTE REAL}

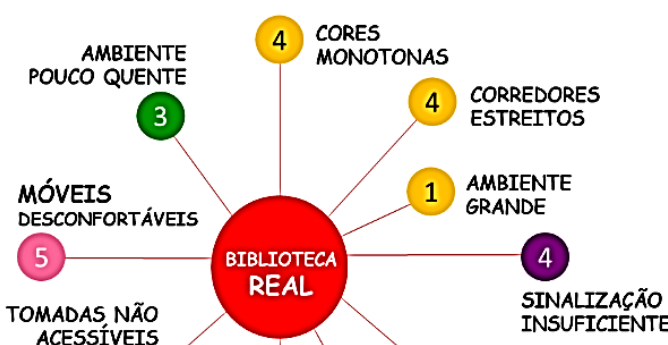

(5)

Fonte: Elaborada pelos autores (2020).

Os resultados demonstraram, que para estes usuários, uma biblioteca ideal deve oferecer um espaço amplo e de boa circulação, área de estudos reservada, um acervo vasto de obras, tomadas acessíveis, mobiliário confortável, paleta cromática estimulante e convidativa, sinalização eficaz do ambiente e do acervo, ambiente climatizado e sistema de iluminação adequado.

\section{Diagnóstico ergonômico}

As primeiras impressões denotam um ambiente amplo e iluminado, com condições de atender as necessidades do usuário, oferecendo suporte social com acesso a banheiros, internet, espaços específicos para execução de diversas atividades e boa localização geográfica na área total da universidade, estando perto de múltiplos setores institucionais e sociais do Campus. No entanto, é esteticamente monótono, com uma paleta cromática neutra e fria, que estimula a fadiga em nível psicoemocional como desmotivação, improdutividade intelectual, desânimo e sonolência.

A partir do processo analítico, outras inadequações ergonômicas foram identificadas. Em relação ao conforto ambiental, a iluminação diurna apresenta pontos excessivos - próximos a janelas - com muita incidência solar, podendo causar desconforto visual, principalmente a quem possuir astigmatismo. A temperatura e o ruído, encontram-se em níveis insatisfatórios ultrapassando as recomendações da literatura. Ainda sobre o ruído, o barulho dado pela movimentação dos transeuntes compromete a concentração e desempenho cognitivo dos usuários da cabine, uma vez que o espaço de estudo não é separado do espaço comum do ambiente.

A interação com o ambiente e o mobiliário suscita a ocorrência de situações e posturas inadequadas, que podem ser voluntárias, pelo uso indevido, ou involuntárias, quando induzidas pelo aspecto físico e funcional do espaço e mobiliário. A biblioteca dispõe de cadeiras pesadas, sem apoio para braços e nem mecanismo de regulagem; estantes que incitam o esforço da coluna vertebral, do pescoço e das articulações do joelho, por apresentarem prateleiras muito altas ou baixas demais. Também ficou evidente a configuração de corredores inadequados para circulação simultânea de andantes ou 


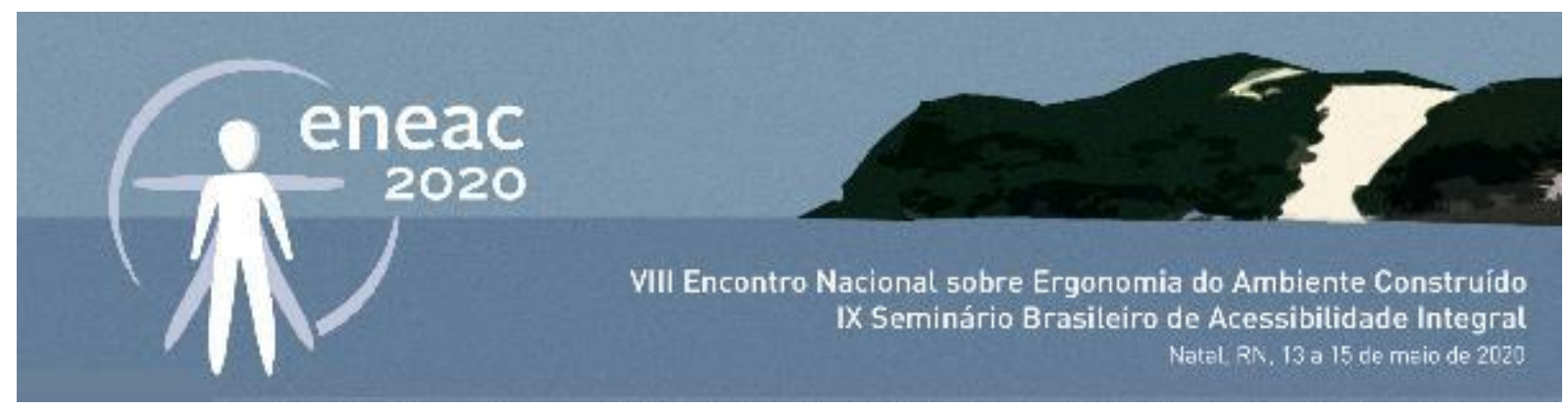

cadeirantes, bem como pilares que atrapalham a circulação e variação do leiaute do espaço. A investigação identificou fiações elétricas expostas com perigo de acidentes elétricos ou mecânicos; também se verificou tomadas elétricas instaladas no rodapé da parede das cabines, as quais dificultam o acesso provocando posturas nocivas e/ou acidentes; tais tomadas também envolvem o risco de contato com líquidos eventualmente presentes no piso. Sob um aspecto organizacional, notou-se a falta de um sistema informativo dos títulos do acervo, bem como a ausência de uma saída de emergência em casos de impossibilidade do acesso principal.

Quanto à acessibilidade, foram percebidas a ausência de piso podotátil direcional e de um sistema de sinalização inclusiva. Viu-se ainda que organização de livros não considera uma altura de acesso para cadeirantes, além das cabines de estudos individuais não apresentarem dimensões que comportem adequadamente uma cadeira de rodas.

\section{Recomendações Ergonômicas para o Ambiente}

A investigação tornou possível a identificação de inadequações preocupantes, as quais permitiram a elaboração de recomendações corretivas consoantes às necessidades dos usuários e às possibilidades de uma instituição pública federal. Neste sentido, listou-se recomendações para o ambiente interno da biblioteca. A essência das recomendações envolve a necessidade de uma mudança no leiaute da biblioteca, rearranjando setores e mobiliário, a fim de aumentar o espaço entre os elementos do ambiente e a área de circulação dos usuários, além de outros pontos listados a seguir:

- Reposicionar e substituir a porta de acesso, por um modelo em corrediça e maior; construir uma saída de emergência com portas com acessibilidade;

- Realocar um dos pares do sensor de segurança para o lado externo da porta de acesso;

- Reorganizar as estantes: as grandes devem ser conectadas e formarem corredores; as menores devem ser alinhadas com os pilares; e 1 média deve ser retirada e enviada ao depósito da universidade; Os 4 primeiros corredores devem apresentar 1,50m de largura e o 50 corredor, ao sul do prédio, deve apresentar 1,30m de largura;

- Incluir estantes nos espaços vagos, inclusive abaixo e ao lado das janelas ao norte do prédio, as quais podem ser produzidas na própria oficina de marcenaria do Campus;

- Criar uma área reservada para estudo, evitando a interferência dos transeuntes e oferecendo conforto ambiental durante o desempenho da tarefa;

- Alterar altura de fixação das tomadas para pontos com altura confortável ao acesso manual dos usuários; Executar manutenção do sistema de fiação elétrica, embutindo os fios expostos na estrutura do prédio;

- Reformar as mesas das cabines, oferecendo mesas de alturas de tampo distintas para adequação de usuários de várias dimensões corporais;

- Substituir as cadeiras por modelos leves, reguláveis, com braço e compatíveis as normas ergonômicas e realocação das cadeiras existentes para áreas de convivência da universidade;

- Implantar sistema em Braille sobre áreas de transmissão de informação e sinalização; 


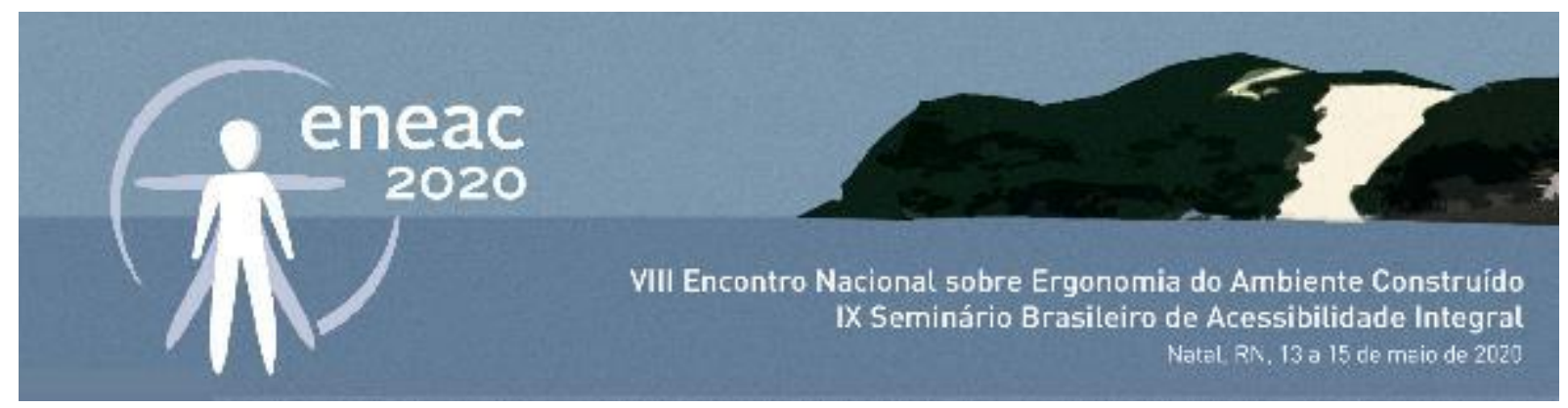

- Aplicar piso podotátil para direcionamento de usuários com deficiência visual;

- Instalar cortinas persianas nas janelas das áreas de atendimento, estudo e consulta eletrônica, para controle da incidência solar sobre o usuário e computadores;

- Executar conserto/manutenção de aparelhos condicionadores de ar para ajuste da temperatura do ambiente;

- Aplicar revestimentos nas paredes, os quais diminuam a reverberação do som;

- Ampliar o sistema de sinalização da biblioteca, para identificação precisa e eficiente dos materiais do acervo. Utilizar os pilares como suporte para elementos de sinalização;

- Aplicar uma nova paleta de cores equilibrada que promova tranquilidade, entusiasmo e iluminação, como exemplifica a figura 8. As cores neutras aplicadas nas paredes maiores, teto e piso e as cores quentes e frias nas janelas, pilares, vigas, detalhes na decoração e no mobiliário e nas paredes menores leste e oeste do prédio.

Figura 8: Paleta de cores recomendada a biblioteca.

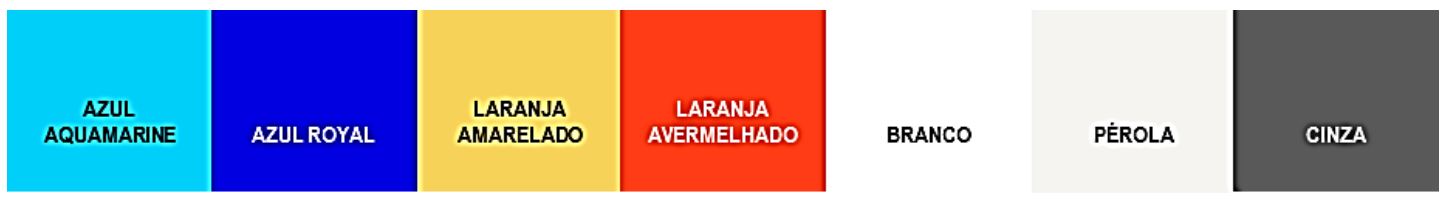

Fonte: Autores Elaborada pelos autores (2020).

Em posse das recomendações listadas, um novo leiaute proposto como correção foi projetado e sua representação foi apresentada em CAD, o qual pode ser acompanhado através da imagem que se segue (figura 9).

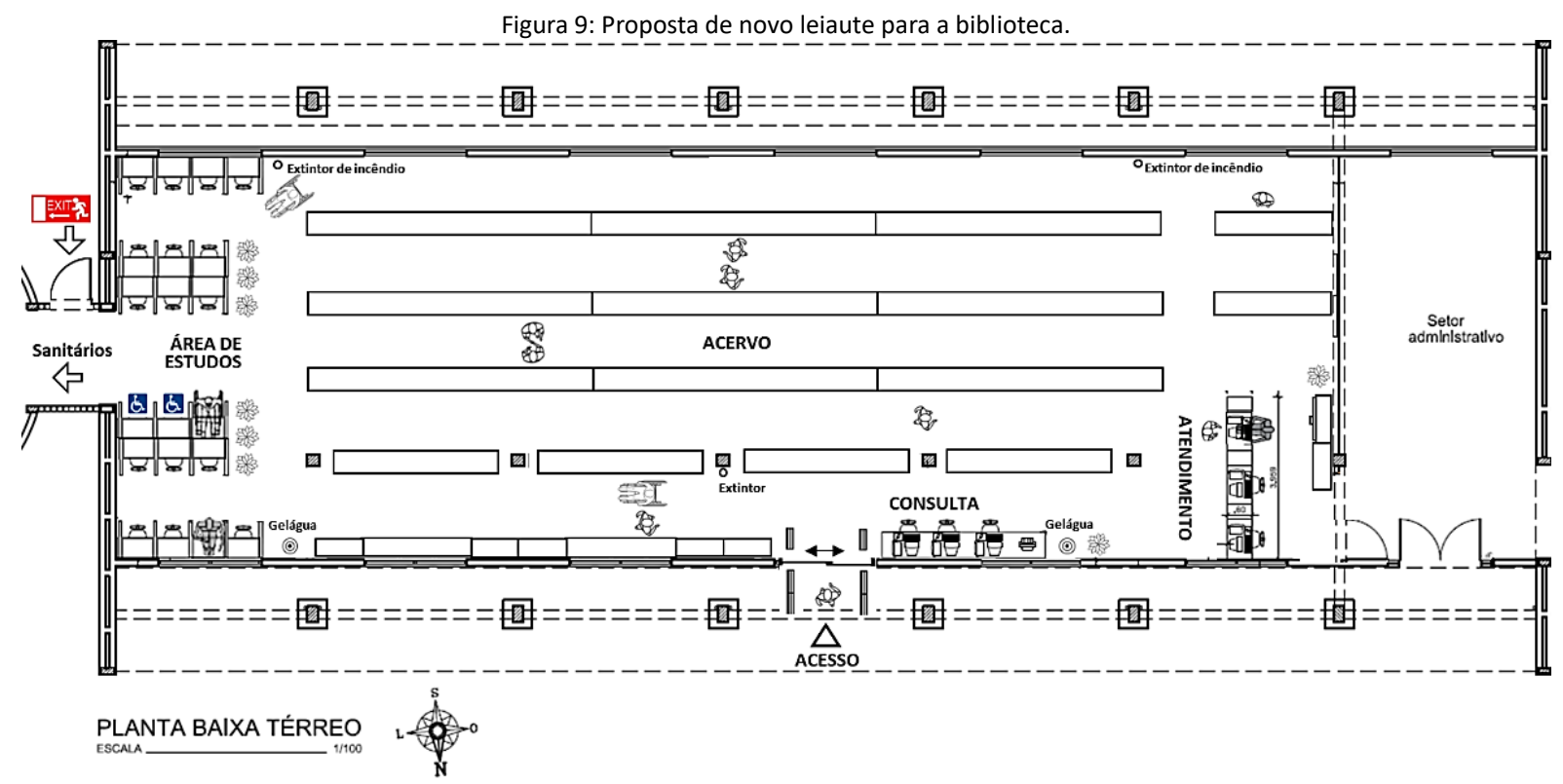

Fonte: Elaborada pelos autores (2020). 


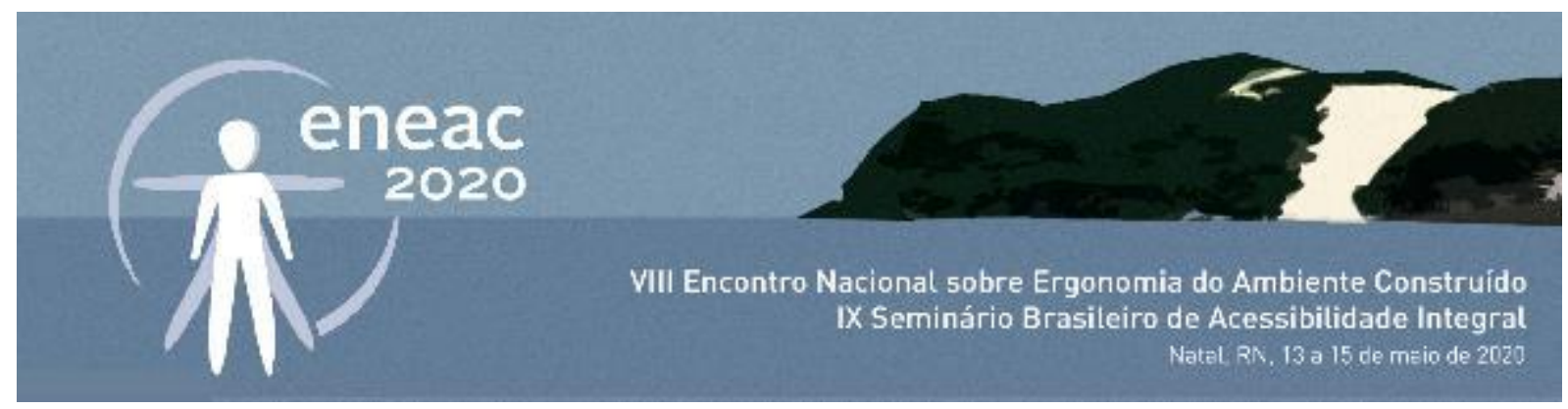

\section{CONCLUSÃO}

A construção do conhecimento humano é alicerçada pelo estudo e pela educação. A educação promove a socialização do ser humano através do conhecimento em um processo contínuo de construção das faculdades físicas e intelectuais. A educação superior desenvolve profissionalmente indivíduos preparados para uma boa colocação no mercado de trabalho, os quais alcançarão um melhor retorno financeiro, bem como promove a evolução do próprio país em diversos aspectos, por meio de pesquisas e descobertas científicas. Neste sentido, desconsiderar as condições em que se constrói este conhecimento dentro das instituições superiores de ensino é comprometer a qualidade do futuro profissional e, como isso, o desempenho integral do próprio país.

As informações apontadas pelo corrente estudo exemplificam o quanto a Ergonomia precisa ser considerada na concepção dos espaços e instituições de ensino superior públicas brasileiras. 0 processo de disseminação de novos campi parece não ter foco no usuário ou nos impactos decorrentes da relação usuário ambiente construído, mas sim, na rápida instalação de edificações que comportem carteiras e lousas. Uma biblioteca deve ser um espaço onde seja prazerosa a busca por novos conhecimentos, entretanto o estudo apontou falhas como a impossibilidade de transitar nos corredores estreitos ou até mesmo dificuldades de ler devido o ofuscamento, atividades básicas neste tipo de ambiente. As diversas inadequações detectadas na investigação revelam a necessidade de se exigir que o governo brasileiro sugerisse que as propostas de novas edificações elaboradas pelas reitorias de cada universidade considerassem o ser humano como centro de projeto. A partir de então se recomendaria que os centros acadêmicos de cada campus pudessem estabelecer uma comissão de avaliação ergonômica das instalações, a qual ficaria responsável por verificar possíveis inadequações tanto em fase projetual, como nos espaços já edificados.

Apesar do contexto de universidade pública, que lida com muitas questões governamentais burocráticas, neste estudo, foi possível encontrar soluções de exequibilidade acessível para adequação do ambiente, otimizando a usabilidade do espaço para a comunidade acadêmica. Para tanto, a metodologia MEAC se revelou bastante eficaz, conduzindo a equipe de pesquisa à identificação de falhas nas diversas áreas que as atividades envolviam. A abrangência das recomendações ergonômicas tecidas ao fim da investigação só foram possíveis graças a aplicação da metodologia ter proporcionado a identificação de diversas inadequações no espaço.

\section{REFERÊNCIAS}

ALCÂNTARA, F. L. C.; BERNARDINO, M. C. R. O papel da biblioteca universitária como mediadora no processo de ensinoaprendizagem nas bibliotecas universitárias na cidade de juazeiro do norte - CE. In: Encontro Regional de Estudantes de Biblioteconomia, Documentação, Ciência e Gestão de Informação - EREBD N/NE, 15-21 jan. 2012. Disponível em: <http://portaldeperiodicos.eci.ufmg.br/index.php/moci/article/viewFile/2016/1288> Acesso em: 11 de setembro de 2019.

ASSOCIAÇÃO BRASILEIRA DE NORMAS TÉCNICAS. NBR 10152 - Níveis de ruído para conforto acústico. Rio de Janeiro, p. 4. Disponível em: <http://www.joaopessoa.pb.gov.br/portal/wp-content/uploads/2015/02/NBR_10152-1987-ConfortoAc_stico.pdf> Acesso em: 11 de setembro de 2019.

ASSOCIAÇÃO BRASILEIRA DE NORMAS TÉCNICAS. NBR 5413 - Iluminância de interiores. Rio de Janeiro, p. 13. Disponível em: <http://ftp.demec.ufpr.br/disciplinas/TM802/NBR5413.pdf> Acesso em: 10 de setembro de 2019.

ASSOCIAÇÃO BRASILEIRA DE NORMAS TÉCNICAS. NBR 6401 - Instalações centrais de ar-condicionado para conforto Parâmetros básicos de projeto. Rio de Janeiro, p. 17. Disponível em: 


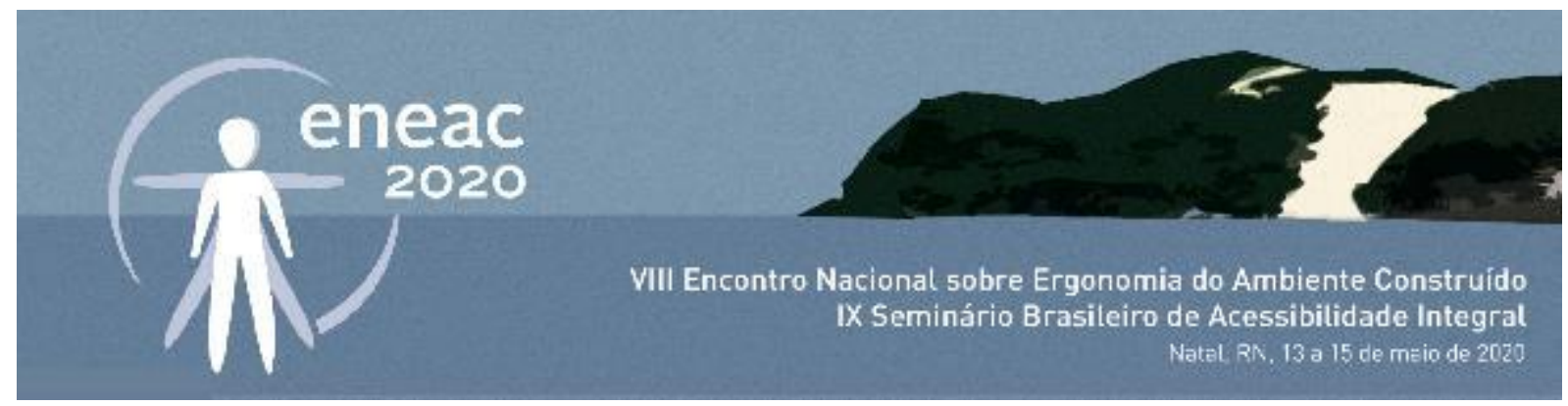

<https://www.refrigeracao.net/Legislacao/NBR6401.pdf> Acesso em: 10 de setembro de 2019.

ASSOCIAÇÃO BRASILEIRA DE NORMAS TÉCNICAS. NBR 9050 - Acessibilidade a edificações, mobiliário, espaços e equipamentos urbanos. Rio de Janeiro, p. 105. Disponível em:

<http://www.turismo.gov.br/sites/default/turismo/o_ministerio/publicacoes/downloads_publicacoes/NBR9050.pdf > Acesso em: 10 de setembro de 2019.

AZEVEDO, M. de F. M. de; SANTOS, M. S. dos; OLIVEIRA, R. de. Uso da cor no ambiente de trabalho: Uma ergonomia de percepção. Disponível em: <https://pt.slideshare.net/gutoffline/o-uso-da-cor-no-ambiente-de-trabalhouma-ergonomia-dapercepcao> Acesso em: 12 de setembro de 2019.

EMERIM, L. D. Condições de Conforto Ambiental para Usuários: Estudo de caso na Biblioteca Central Irmão José Otão. 147 p. Universidade Federal do Rio Grande do Sul. Faculdade de Biblioteconomia e Comunicação. Porto Alegre,2016. Disponível em: <https://www.lume.ufrgs.br/bitstream/handle/10183/147265/000999155.pdf?sequence=1\&isAllowed=y > Acesso em: 20 de dezembro de 2019.

GONÇALVES, M. F. da C. do C. O uso da cor na arquitectura contemporânea: qualificação do espaço arquitectónico em edifícios escolares. 119 p. Faculdade de Arquitectura e Artes da Universidade Lusíada de Lisboa. Lisboa, 2016. Disponível em: <http://repositorio.ulusiada.pt/bitstream/11067/2711/1/mia_marta_goncalves_dissertacao.pdf> Acesso em: $12 \mathrm{de}$ setembro de 2019.

IIDA, Itiro. Egonomia: projeto e produção. 2a edição. São Paulo: Edgard Blucher, 2005.

LACY, M. L. O poder das cores e o equilíbrio dos ambientes. 7. ed. São Paulo: Pensamento, 2000. Disponível em: $<$ https://fdocumento.com/document/o-poder-das-cores-no-equilibrio-dos-ambientes.html> Acesso em: 20 de dezembro de 2019.

MINISTÉRIO DO TRABALHO E PREVIDÊNCIA SOCIAL. NR 17. Ergonomia. p. 14. Disponível em: \&lt;https://www.pncq.org.br/uploads/2016/NR_MTE/NR\%2017\%20-\%20ERGONOMIA.pdf\&gt; Acesso em: 10 de setembro de 2019.

MINUZZO, L. U.; SANTOS, J. P. Proposta de um programa de necessidades para a nova sede da Biblioteca Pública do Estado do Rio Grande do Sul. 157 p. Universidade Federal do Rio Grande do Sul. Faculdade de Biblioteconomia e Comunicação. Porto Alegre, 2004. Disponível em: <https://www.lume.ufrgs.br/handle/10183/33049> Acesso em: 12 de setembro de 2019. PANERO, J.; ZELNIK, M. Dimensionamento humano para espaços interiores. 1. Ed. Barcelona: Gustavo Gilli, SL, 2016.

PIMENTEL, G.; BERNARDES, L.; SANTANA, M. Biblioteca escolar. Universidade de Brasília. Brasília, 2007. 117 p. Disponível em: <http://portal.mec.gov.br/seb/arquivos/pdf/profunc/biblio_esc.pdf> Acesso em: 11 de setembro de 2019.

SANTOS, J. R. dos; FREITAS, A. Á. de; BARROS, A. J. de; PASSOS, C. V. Estudo de caso, a influência das cores de tintas aplicadas em obras civis sobre o ambiente e os seres humanos em João Monlevade Minas Gerais /Brasil. Revista Contribuciones a las Ciencias Sociales, Abr.-Jun. 2017. Disponível em:

<http://www.eumed.net/rev/cccss/2017/02/tintas.html> Acesso em: 20 de dezembro de 2019.

SOUTO, G; MARX,R.; PEDREIRA, Z. Cores para bibliotecas. 1999. In: CAPRI, D.; BAHIA, E. M. dos S.; PINTO, A. L. Ergonomia: estudo de caso em biblioteca universitária. Biblios Online, p. 41-54, Ago. 2012 Disponível em:

$<$ https://www.researchgate.net/publication/304469861_Ergonomia_estudo_de_caso_em_biblioteca_universitaria > Acesso em: 12 de setembro de 2019.

VASCONCELOS, C. S. F. e; VILLAROUCO, V.; SOARES, M. M. Avaliação Ergonômica do Ambiente Construído: Estudo de caso em uma biblioteca universitária. Ação ergonômica, Revista Brasileira de Ergonomia, v. 4, n. 1, p. 5-25, 2009. Disponível em: <http://www.abergo.org.br/revista/index.php/ae/article/view/69> Acesso em: 11 de setembro de 2019.

VILLAROUCO, V. O ambiente está adequado? Anais do ENEAC 2007: I Encontro Nacional de Ergonomia do Ambiente Construído e II Seminário Brasileiro de Acessibilidade Integral. Recife, 2007.

VILLAROUCO, Vilma. An ergonomic look at the work environment. In: Proceeding from IEA 09: 17th World Congress on Ergonomics. China: Beijing, 2009. 